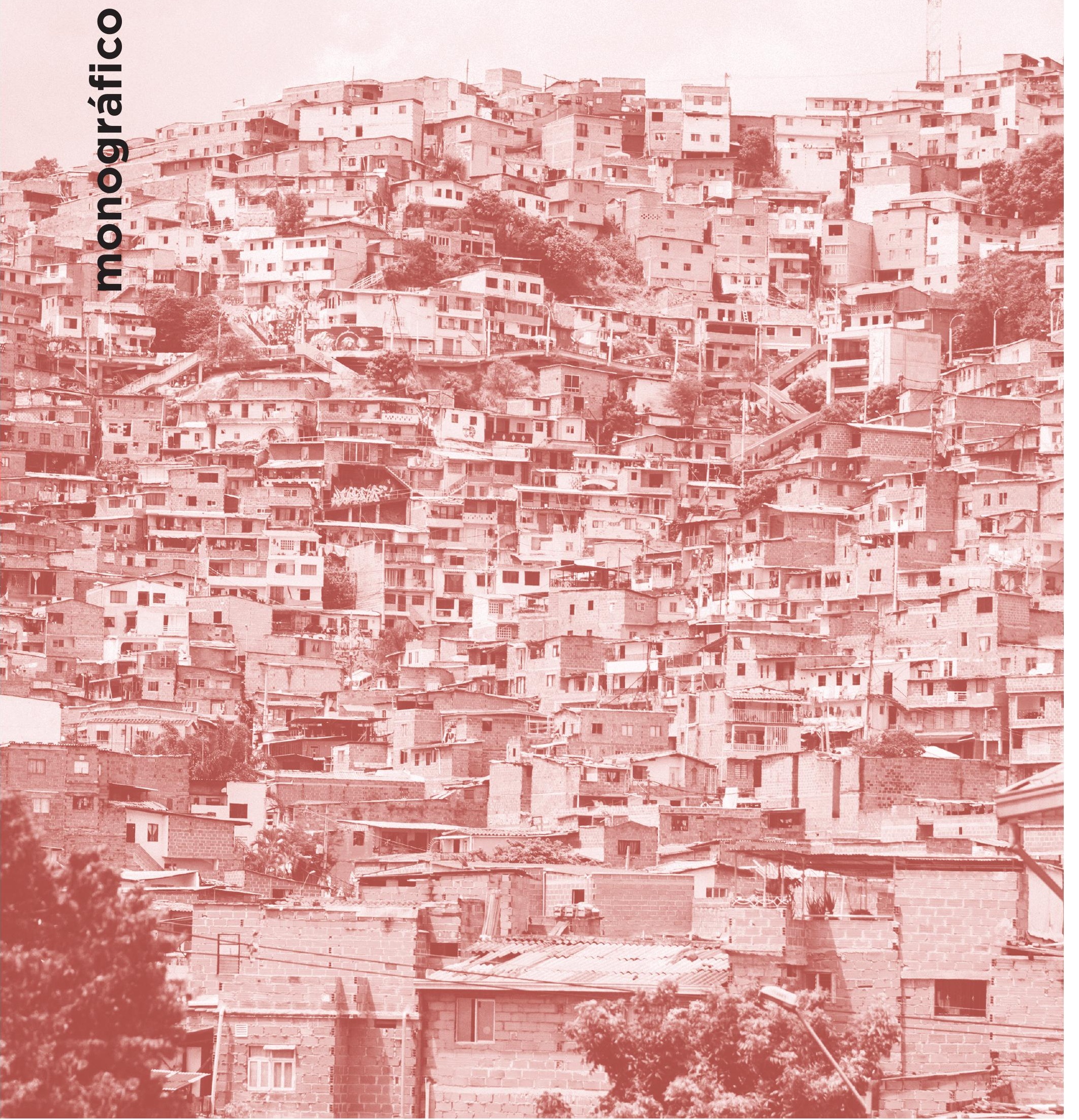




\section{El papel de la cultura en la construcción de paz y en el desarrollo teritorial de Colombia}

\section{Luis Manuel Úsuga Samudio’}

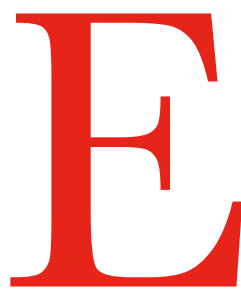

1 definitivo papel de la cultura en la construcción de diversos procesos que ayudaron a consolidar la «convivencia ciudadana» como uno de los baluartes imprescindibles para el desarrollo del proceso de paz, es contado en este artículo por una de las personas que más ha trabajado por su implementación. Colabora desde hace muchos años en la puesta en marcha de procesos culturales como herramientas para la construcción de ciudadanías activas. Cree en la cultura como los pájaros creen en el aire, de una manera casi «irracional» pero cargada de razones, que son las que poco a poco va desgranando en este artículo tan emotivo como cargado de argumentos para entender el verdadero papel de la cultura en la reconstrucción del tejido social colombiano.

El 13 de marzo de 1988 se realizó la primera elección popular de alcaldes y gobernadores en Colombia ${ }^{2}$. Lo recuerdo muy bien. Antes, los alcaldes eran designados por los gobernadores, quienes, a su vez, eran nombrados por el presidente de la República. A pesar de que este tenía en cuenta a los senadores elegidos popularmente, pocas veces se aplicaban criterios que reflejaran la voluntad o las necesidades de los habitantes de los territorios ${ }^{3}$. La descentralización admi- nistrativa permitió que los gobernantes locales tuvieran mejores herramientas para implementar modelos consecuentes con las particularidades de los territorios. También permitió que los ciudadanos pudieran cambiar el rumbo de la ciudad cuando los elegidos no hacían bien su trabajo ${ }^{4}$.

Treinta años después de iniciado este proceso, siguen existiendo asimetrías en la participación regional y enormes retos para que se apliquen plenamente las herramientas con que cuenta el país en materia de descentralización. Por otra parte, la participación ciudadana, gestora del desarrollo territorial, es perseguida, como lo muestra la sistemática desaparición de líderes sociales en los últimos años en el país

Esta terrible tragedia sucede después del proceso de paz suscrito con la guerrilla de las FARC. Esta fuerza militar que contaba con 15.700 personas armadas ${ }^{5}$, se desactivó en territorios que fueron ocupados en algunos casos por disidentes que no quisieron desmovilizarse y mayormente por criminales organizados. Los líderes sociales inmolados, en su mayoría, trabajaban en procesos de restitución de tierras arrebatadas por la guerrilla, los paramilitares o por terratenientes, y defendiendo ecosistemas destruidos por la minería ilegal y los cultivos ilícitos. Este fenómeno solo se puede explicar desde la cultura y, por supuesto, solucionar a través de 
ella. La violencia ha estado presente durante toda la historia de nuestro país y a pesar de que se cambian periódicamente las justificaciones políticas o económicas, en esencia se preserva el método: la eliminación de la persona que piensa diferente. Este mecanismo forma parte de los imaginarios que inspiran a los integrantes de los bandos en conflicto y a una buena parte de la comunidad.

\section{El proyecto de nación del siglo pasado}

En los años sesenta y setenta la construcción de ciudadanía y de los valores de la nación correspondían a un proyecto gubernamental centralista que desconocía la diversidad y plurietnia colombiana. Para este fin, el gobierno usaba las dos cadenas de televisión y la emisora nacional pública; Inravisión y la Radiodifusora Nacional promovían la música de la región andina (Bambuco, Pasillo, Güabina) como la música colombiana, desconociendo y subestimando músicas tan poderosas como las del pacífico, la cumbia, la llanera y el vallenato. La pretensión de esta estrategia era la implementación de un relato dominante del centro del país y de una cultura criolla blanca que reivindicaba derechos coloniales ya extintos por aquellas fechas. Colcultura, que era la institución nacional responsable de apoyar y promover el desarrollo cultural en la nación, en su primera década (existió desde 1968 hasta 1997) apoyaba principalmente las bellas artes y la música andina colombiana. Este conjunto de manifestaciones era considerado «cultas» por el gobierno y lo culto era moderado, elegante, no soez, no popular. Era un relato de la élite para sostener su posición dominante.

En contraste, desde los años setenta se vivió una fuerte politización en las artes. La revolución cubana alimentó el fuego de los procesos insurgentes de la región. En Colombia, muchos grupos teatrales, músicos y escritores rompieron los marcos trazados desde las políticas públicas y se convirtieron en poderosos vehículos de comunicación de las organizaciones políticas y guerrilleras de izquierda. El boom latinoamericano con Cortázar, Vargas Llosa, García Márquez y otros enaltecía las propias culturas y denunciaba la inequidad, reclamando justicia social. Se conformaron grupos de teatro con siglas similares a las de la guerrilla: Teatro Experimental de Cali TEC, Teatro Popular de Bogotá, Teatro Popular de Medellín, La Candelaria y otros. La nueva trova cubana, la música popular brasilera y la canción protesta fueron el marco para los artistas nacionales. Pablus Gallinazo, Ana y Jaime, Grupo Suramérica y Jorge Veloza, entre otros, denunciaron la opresión de los gobiernos y convocaron la movilización social.

\section{El apocalipsis según Pablo}

En los años ochenta se consolidó el enormemente lucrativo negocio del narcotráfico. En Colombia, especialmente en el norte del país, desde los años setenta, se cultivaba marihuana. Esta era exportada ilegalmente hacia Estados Unidos. En la siguiente década se dieron cambios culturales y estéticos que afectaron los gustos de los consumidores estadounidenses. La cocaína se impuso a la par de un aumento enorme de la población que la demandaba. Este negocio producía astronómicas ganancias a los criminales que lo dominaban en todo su ciclo de producción: cultivo en las selvas de Bolivia, Perú, Brasil y Colombia, rutas de transporte y en su venta por mayoreo en Norteamérica y Europa. Este próspero ecosistema gestó narcotraficantes altamente competitivos que se aliaron en carteles que debilitaron la ya precaria institucionalidad existente en esta época.

Esta década fue también el escenario en el que se crearon las autodefensas campesinas, organismos conformados por víctimas de una guerrilla dogmática y extremista que asesinó y empobreció a terratenientes y gente humilde de los campos. Los diversos grupos guerrilleros que existían habían nacido y se habían consolidado por décadas en un país pobre e inequitativo que no brindaba esperanzas a sus habitantes, pero también se habían agotado políticamente y en muchos de los territorios que ocupaban perdieron las simpatías de los pobladores.

Luego de que el grupo guerrillero M-19 secuestrara a Martha Nieves Ochoa, hermana de una poderosa familia de narcotraficantes, algunos miembros del «establecimiento» ${ }^{6} \mathrm{se}$ asociaron con los narcotraficantes y crearon el MAS (Muerte a Secuestradores). En el proceso de implementación, los narcotraficantes se unieron a las autodefensas. Estas nunca volvieron a detentar su carácter político o su enfoque de defensa de los campesinos. Se convirtieron en una organización criminal que derivó su sustento del narcotráfico y que justificó su existencia como la única forma de conservar el orden de la nación.

Puede que este momento haya sido el de mayor desesperanza en Colombia. La tasa de homicidio de Medellín, la segunda ciudad del país, era superior a la de muchos países en guerra. En un análisis realizado por el sociólogo Max Yuri Gil Ramírez, entre los años de 1975 y 2018 la ciudad registró 98.500 homicidios, desde 1976 la tasa siempre ha sido superior a veinte homicidios por cada 100.000 habitantes. La OMS considera que cuando hay una tasa superior a diez, hay una situación de violencia epidémica. ${ }^{7}$ 


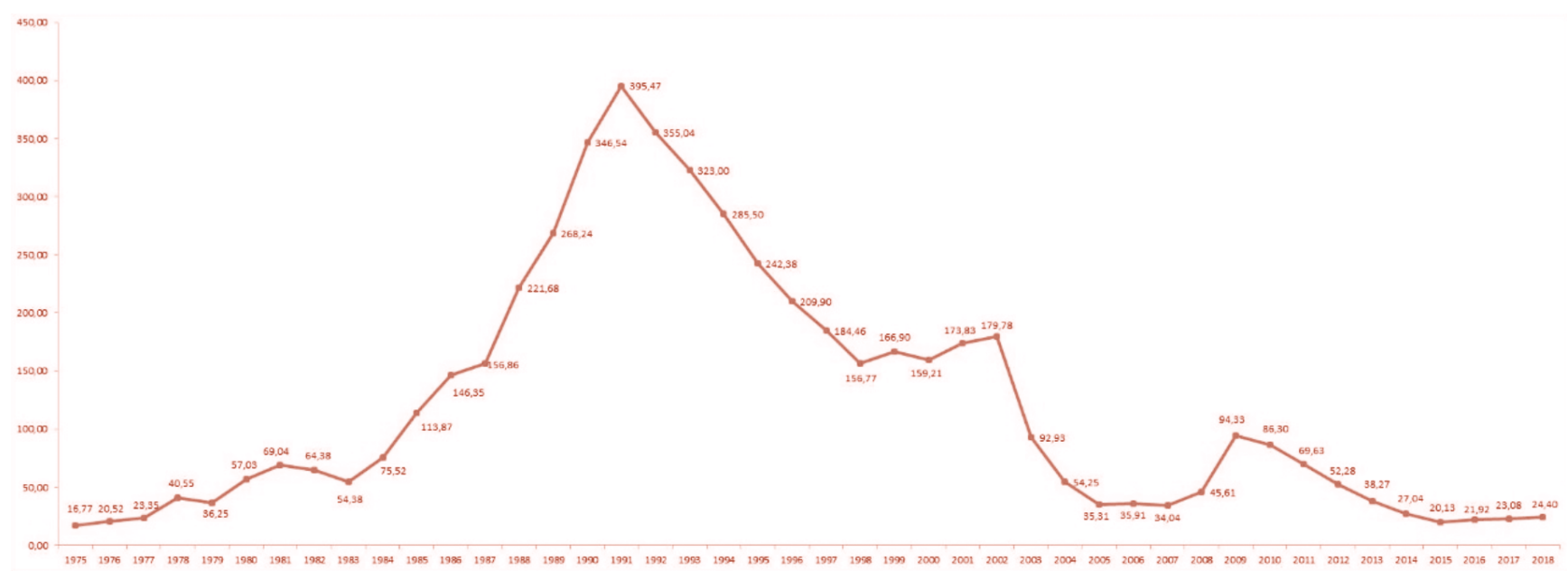

Ilustración 1. Evolución de la tasa de homicidio en Medellín - Max Yuri Gil Ramírez. Datos suministrados por el SISC.

\section{De lo político a lo estético}

Muchos colombianos entendimos que más de trescientas mil muertes violentas producidas entre las décadas del cincuenta y del ochenta, en medio del fragor de una guerra civil denominada «época de la violencia», y el posterior conflicto protagonizado por las guerrillas de las FARC, M-19, EPL, Quintín Lame y otros, no produjeron, ni iban a producir los cambios sociales que reclamaba el país. Por el contrario, se constató que el balance desfavorecía a las poblaciones más vulnerables de los campos y las ciudades. En respuesta, muchos creadores y organizaciones culturales desvincularon sus objetivos de las organizaciones políticas legales e ilegales. Se privilegió el arte y la vida. Un acontecimiento importante de estas nuevas formas lo representó el Festival Latinoamericano de Teatro de Manizales (el más antiguo de América) que desde 1984 concentró su guion más en lo estético que en lo político.

El trabajo de las organizaciones culturales de Medellín ilustró este nuevo enfoque de manera clara. En 1987, un entusiasta grupo de jóvenes liderado por Jorge Blandón, fundaron la Corporación Cultural Nuestra Gente. Esta organización tiene su sede en el empinado barrio Santa Cruz. La compraron con recursos propios, vendiendo paletas y empanadas en el estadio, gestionando recursos con organizaciones de cooperación internacional y gobiernos locales. En esta casa de color amarillo hacen teatro, música, danza y se pelean con las bandas criminales del sector por los jóvenes. Este espacio ha ofrecido alternativas de vida diferentes a las de las bandas de sicarios, de las milicias urbanas, de los paramilitares y de las organizaciones criminales que azotan al barrio hasta los días de hoy. Gozan del respeto de la comunidad y esta legitimidad los ha blindado de los asesinos que siguen siendo la influencia principal en el territorio.

Los conflictos por los territorios de las bandas de narcotraficantes afectaban particularmente a los habitantes de los barrios de Medellín. Se delimitaron fronteras invisibles que no podían ser traspasadas por los vecinos. En los límites permanecían, apostados, jóvenes armados que tenían la orden de asesinar a cualquiera que desconociera esa frontera. En 1990, el grupo Barrio Comparsa decidió traspasar con su acto festivo comunitario, en zancos, con saltimbanquis y su alegre percusión, la frontera del barrio Manrique (uno de los más peligrosos). Los sicarios no dispararon. En el siguiente barrio: Aranjuez, se encontraron con otra comparsa y siguieron recorriendo la ciudad. A partir de ese momento se institucionalizó un respeto generalizado por parte de los sicarios hacia los artistas que trabajaban en los barrios.

El famoso narcotraficante Pablo Escobar en la década de los ochenta arrojó desde una avioneta unos volantes en los que conminaba a la población de Medellín a no salir después de las nueve de la noche, so pena de ser asesinados por sus sicarios. La ciudadanía sabía, sin atisbo de duda, que esta amenaza iba a ser ejecutada y atendieron la orden. Se demostraba la existencia de un Estado paralelo que domina- 
ba el territorio con sus dos millones de habitantes. El teatro Matacandelas, una organización cultural ubicada en el centro de Medellín programó por esos días una temporada de la obra de Fernando Pessoa "Oh Marinheriro" a las 12 de la noche en abierto desacato a la orden del mafioso. La asistencia de público fue copiosa y aunque muchos de los espectadores se quedaron en las instalaciones del teatro hasta que amaneció, por miedo a ser asesinados en la calle, el hecho tenía una fuerza simbólica muy poderosa.

Esos tiempos también fueron testigos del nacimiento del Festival de Poesía de Medellín. Desde sus inicios en 1991 todas las versiones se han realizado en el espacio público, en la calle, con poetas de todo el mundo, varios premios nobel, que se han solidarizado con la tragedia que ha afectado a la ciudad y también ha servido como canal para que más de treinta mil medellinenses, de forma ritual, hasta hoy, todos los años, retomen el espacio que les había sido arrebatado.

En 1990 el escritor y periodista Alonso Salazar publicó $\mathcal{N}_{0}$ nacimos pa semilla, una obra que permite atisbar la realidad de los jóvenes de la ciudad y las razones que gestaron el fenómeno del sicariato. Desde el cine, Víctor Gaviria nos ofrece una visión de la realidad de los jóvenes con la película "Rodrigo D No futuro" en la que el arte es expuesto como una herramienta que permite comprender los imaginarios juveniles. Estos dos trabajos, que retrataron la enorme tragedia humanitaria que agobió a la juventud de Medellín, contaron con una masiva aceptación por parte del público y se constituyen en hitos mediante los cuales se pueden emprender soluciones diferentes a las del uso de las armas por parte del Estado.

Este escenario de crisis fue el caldo de cultivo en el que germinaron proyectos culturales y sociales que desde la sociedad civil pusieron en evidencia que el gobierno no contaba con el modelo ni con el vigor para enfrentar la crisis.

El gobierno del presidente César Gaviria Trujillo (1990-1994), en medio de este turbulento escenario, creó una novedosa estructura denominada Consejería Presidencial para Medellín y su Área Metropolitana, liderada por la periodista María Emma Mejía. Por primera vez el gobierno nacional descentralizó su poder, desplazándolo hasta el propio escenario del conflicto y valiéndose de la experiencia y la legitimidad en el territorio de las organizaciones sociales y culturales. Esta estrategia, sumada a la constituyente (1991) y al fortalecimiento de la institucionalidad, permitió pasar la hoja de la violencia que instituyeron los carteles de la droga.

En el período que siguió al desmonte de las estructuras criminales de Pablo Escobar y del Cartel de Cali, se consolidaron nuevas fuerzas como la Oficina de Envigado y la Banda de la Terraza que agruparon a los lugartenientes de los anteriores capos y se apropiaron de las rutas y mercados de la droga que quedaron disponibles. A pesar de que disminuyó drásticamente la violencia de las organizaciones delincuenciales, esta no desapareció totalmente. Las guerrillas, que desde su creación habían permanecido principalmente en el campo, se sumaron a este escenario con la conformación de milicias urbanas que detonaron una confrontación con las bandas criminales que tenían puesto el chaleco del paramilitarismo para justificar políticamente su accionar militar.

El clímax de este conflicto se dio el 16 de octubre de 2002 en la comuna 13, en el occidente de la ciudad, con la operación Orión. Esta acción militar duró dos días. Fue una batalla campal en la que las fuerzas armadas colombianas rodearon varios barrios de la ciudad con el apoyo de helicópteros artillados que realizaron bombardeos urbanos. El último reducto de guerrilleros urbanos fue exterminado y se ha comprobado que se recibió apoyo de los paramilitares. La operación fue ordenada por el presidente Álvaro Uribe Vélez. En ese terrible escenario, de nuevo, surgieron organizaciones culturales que brindaron alivio a las comunidades afectadas por este conflicto.

El artista plástico y rapero Aka, fomenta en la comuna 13 una (r)evolución de ciudad. Creó el proyecto AgroArte, que construye tejido social, resistencia, memoria y seguridad alimentaria. En los lugares donde han asesinado personas (principalmente jóvenes) han creado huertas que son apropiadas por quienes habitan el barrio, re-significando el sentido que las marcó con el miedo y ofreciendo también alimentos que son consumidos por la comunidad. En este espacio, surgió el Partido de las Doñas, conformado en principio por mujeres, que en muchos casos fueron víctimas; madres, en su mayoría, de jóvenes asesinados o desaparecidos.

Somos el Partido de La Doñas, resultado de la unión de Mujeres que se reconocen como facilitadoras en el camino de la dignidad y la lucha, somos quienes, mediante el amor, defendemos la vida como el valor más sagrado en la ciudad del miedo. Como si fuésemos semillas que el viento esparce, llegamos desde las verdes montañas para florecer en la ciudad, dejando tatuado nuestro carácter en el territorio que nació en nuestras manos, que hemos construido y defendido desde los años en los que la luz aún faltaba y el agua corría sin cauce desde la montaña. Mujeres de campo y ciudad, 
de barrio y vereda ${ }^{8}$, de la historia y sin banderas, que tenemos un método contra el olvido, dentro de nuestra sabiduría tenemos el bálsamo para sanar las heridas del alma, una coraza de valentía para derrotar el miedo mientras nos tejemos en un hilo fuerte que nos une haciéndonos resistentes y resilientes ante la adversidad.

Así como cuidamos de nuestros jardines, somos guardianas de la memoria de la comunidad, una memoria que resiste dignificando la vida, transformando la sociedad, dando voz al oprimido y construyendo nuevas ciudadanías donde no tendrá cabida la demagogia.

Somos maestras de los nuevos ciudadanos, que participan en la construcción de un nuevo país en el que todos y todas contamos.

Todos los ciudadanos y ciudadanas pueden hacer parte del Partido de las Doñas, tenemos actividades semanales y tenemos un banco de tiempo solidario. Otro barrio y otra ciudad es posible con el Partido de las Doñas ${ }^{9}$.

El poder simbólico de este trabajo tiene una incidencia directa en los habitantes del barrio y un gran poder de comunicación hacia el exterior; con las autoridades, la ciudad y el país pueden influir en grupos de opinión para proteger y sanar el territorio.

Tres décadas después de Nuestra Gente, en la comuna 13 y como reacción a la desesperanza, nace Casa Morada. Esta experiencia es comparable con la de la Corporación Nuestra Gente en el sentido de que el espacio (la morada) es la dimensión que vincula al proyecto con la comunidad. Los jóvenes pueden desarrollar sus talentos en un sitio para ensayar música, una emisora, talleres de computación, poesía y otros. Se definen y desarrollan como colectivo, esto permite la construcción de un guion adaptable a los vertiginosos cambios que afectan el entorno. Hacen trabajo político, no hacen proselitismo electoral. En su página exponen unas sugestivas definiciones:

¿Qué es Morada? Somos un colectivo en red sin ganas de hacer negocios, sin ánimo de formalizarnos, ni de corporatizarnos. Somos un colectivo con emisora, con un espacio (o morada material), con actividades, con alianzas para crear, para disfrutar, para encontrarnos. Nos mueve el placer, nos unen unas sensaciones. Si tienes un proyecto artístico, cultural, periodístico, investigativo y necesitas un lugar para crear, para

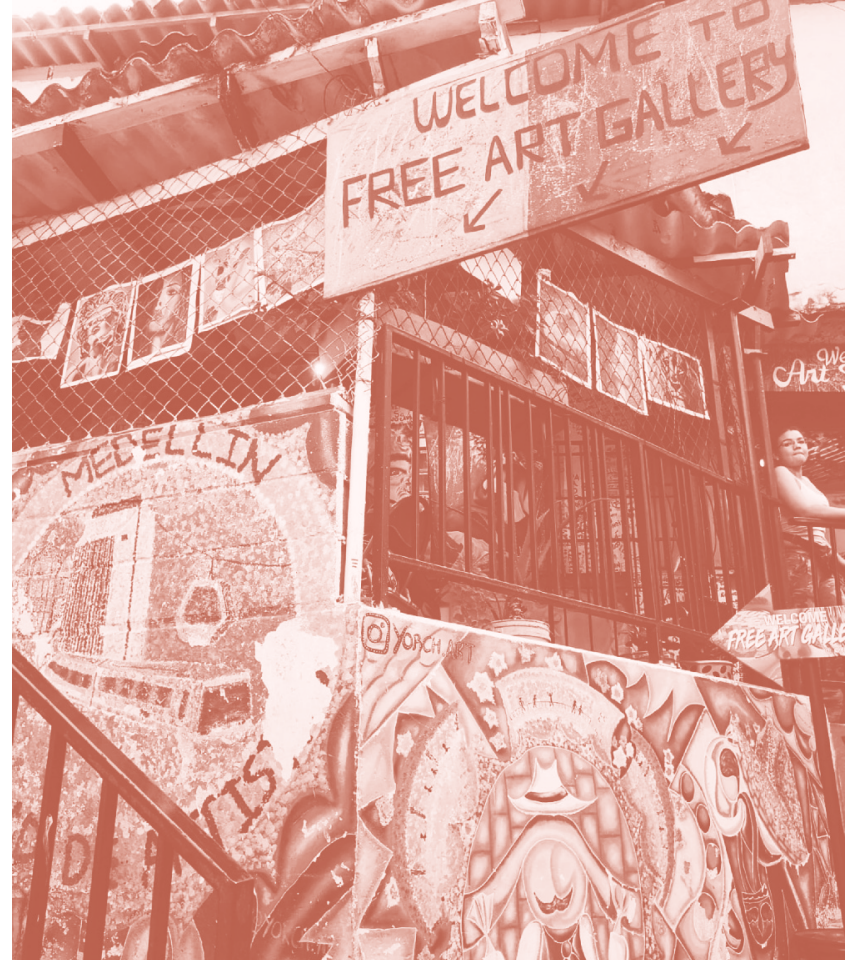

el intercambio, ¡Bienvenido! Nos movemos en red por el voz a voz, tejiendo uno a uno, no somos un espacio público, ni una sede cultural del gobierno

¿Cómo funciona Morada? Morada no tiene director, no tiene jefe, no tiene personería jurídica. Ha sido capaz de sobrevivir por la generosidad, el trueque, el parche, el disfrute, el voluntariado, la pasión. La acumulación no es importante, el monopolio no es un deseo, el control no es una pulsión ${ }^{10}$.

En Medellín y en Colombia existen miles de organizaciones culturales que realizan trabajos similares. En la comuna 13, Jeihhco Castaño ${ }^{11}$, el rapero, se enfrenta con su música a los asesinos de jóvenes. Casa Kolacho ha promovido la realización de una inmensa galería abierta: "Graffiti Tour", en la que los jóvenes artistas narran desde su estética la historia de la tragedia y la esperanza del barrio. Este espacio se ha convertido en un concurrido destino turístico, visitado por personas provenientes del exterior y de otras ciudades de Colombia. Juanes, el reconocido cantante internacional, desde 2010 creó la fundación Mi Sangre para atender a los niños víctimas de las minas antipersonal sembradas en 
los campos por la guerrilla. En Bogotá la fundación Ojo al Sancocho crea un festival de cine con el mismo nombre, en una de las localidades más pobres de la ciudad, para dignificar la diversidad de sus expresiones culturales y artísticas. Sancocho es una sopa típica de Colombia que se prepara con muchos ingredientes diferentes. Los invitados internacionales y nacionales deben alojarse en el barrio, en las casas de los vecinos. Esto ha logrado que se entienda esa realidad cotidiana y comunica a sus habitantes un profundo sentido de dignidad y orgullo.

La clave es la solidaridad. Las personas, los creadores y la comunidad participan en la construcción de la realidad, de las soluciones. El gobierno nacional y los de algunas ciudades han incorporado esos guiones a la oferta pública. El Ministerio de Cultura de Colombia, uno de los más antiguos de América, ha funcionado ininterrumpidamente desde su creación. Esto evidencia que esta institucionalidad es alimentada y sostenida por la sociedad civil y, también, por los sucesivos gobiernos, a pesar de haber sido muy diferentes unos de otros en su filosofía política.

Las dos ciudades más grandes del país no han sido diferentes de la realidad nacional, sino que incluso han sostenido apuestas más grandes por el sector. La Secretaría de Cultura de Medellín ha tenido hasta el 4\% del presupuesto de inversión de la Alcaldía con un presupuesto que no ha sido inferior a los 35 millones de euros anuales y que ha ascendido durante varios períodos a cifras superiores a los 50 millones $^{12}$. La Secretaría de Cultura de Bogotá tiene un sistema de participación con 610 consejeros que actúan como un organismo de consulta y veeduría del gobierno de la ciudad ${ }^{13}$. Estos fueron elegidos con una participación de cuarenta y seis mil electores. La ciudad asigna más del 3\% del presupuesto de inversión y cuenta con una oferta pública estable que no se afecta de manera significativa en los cambios de gobierno. Se destaca un proyecto orquestal que beneficia a más de veinticuatro mil niños. En todos los municipios del país hay un mínimo (muy pequeño) de recursos asignados para cultura lo que ha permitido que haya una oferta consolidada y permanente con más de mil fiestas populares y casas de la cultura en la mayoría de los municipios.

\section{La paz con la guerrilla de las FARC}

El 24 de noviembre de 2016 se acordó la paz entre el gobierno colombiano y las FARC luego de un arduo proceso que había comenzado en 2012. Desafortunadamente en la consolidación del posacuerdo no se concibió, de manera institucional, la articulación con el sector cultural para tra- bajar en los imaginarios de la nación para la reconciliación. Se dieron garantías de manutención durante el proceso de reincorporación a los excombatientes, apoyo jurídico, desarrollo económico, se abrieron espacios para la participación pacífica en política, pero no se trabajó en la construcción de escenarios para la reconciliación desde la perspectiva cultural. El conflicto con las FARC tuvo una duración de más de cincuenta años. El terror cultivado sistemáticamente y padecido por todos los bandos produjo profundas heridas que se deben atender también desde una perspectiva cultural.

En una sociedad tan convulsionada como la de Colombia, la cultura ha demostrado ser un blindaje efectivo en contextos de violencia, que convoca a la acción ciudadana para la construcción de una institucionalidad pertinente.

La Ley General de Cultura 397 de 1997 es la que ha soportado al Ministerio de Cultura desde hace veintidós años. Esta operación consistente y continua ha permitido que entendamos, adoptemos, disfrutemos de nuestra diversidad, reconozcamos, protejamos y aprovechemos nuestra multiculturalidad. Contribuyó a la paz, pero está perdiendo vigor porque la realidad ha cambiado dramáticamente. Los problemas de seguridad son diferentes. El posacuerdo, las empresas criminales transnacionales, la desinstitucionalización y la corrupción, entre otros, reclaman cambios en la estructura del sistema, en la política pública, de manera que se diseñe el guion de manera conjunta, con la participación de las comunidades, de la academia, los empresarios, los creadores y los políticos, para que en los siguientes veinte años curemos de manera consistente nuestras heridas, desarmemos nuestros espíritus y al fin podamos tener paz.

\section{Notas}

(1) Administrador de Empresas de la EAN - Escuela de Administración de Negocios de Bogotá. Posgrado en Gestión de Ciudades y Emprendimientos Creativos de la Universidad Nacional de Córdoba. Corresponsable del diseño e implementación de la Política Pública de Emprendimiento e Industria Cultural y Creativa de Bogotá DC., de la implementación de la Cuenta Satélite de Cultura de Bogotá, del mapeo del sector cultural de Bogotá. Cofundador de la Corporación Cultural Ateneo Porfirio Barba Jacob, presidente de la Red Colombia de productores Culturales, director del Festival Iberoamericano de teatro sede Medellín, director Ejecutivo del Circuito de Salas Teatrales, del Semanario Cultural, director de eventos Culturales de la Alcaldía de Medellín durante el 2007 y Secretario de Cultura Ciudadana de Medellín 2008-2011, director de asuntos locales y parti- 
cipación de la Secretaría Distrital de Cultura, Recreación y Deportes de Bogotá.

(2) Registraduría Nacional del Estado Civil (2013): Comunicado de Prensa No.153 de marzo de 2013, https: / /www.registraduria.gov.co/Se-cumplen-25-anos-de-la-primera.html.

(3) VALENCIA-TELLO, D. y VERA, K. D. C. (2013): Descentralización y re-centralización del poder en colombia. La búsqueda de equilibrios entre la nación y las entidades territoriales, Díkaion, http://dx.doi.org/10.5294/DIKA.2014.23.1.7, 2013.

(4) DNP (2002): "Marco conceptual y resultados de progreso municipal" en Evaluación de la descentralización municipal en Colombia: Balance de una década.

(5) RGN (2014): Nacional, https://noticias.canalrcn. com/nacional-pais/guerrilla-las-farc-contaria-15700-hombres.

(6) Anglicismo establishment, que en Colombia se refiere al conjunto de personas y entidades de la clase dominante que se asocian para conservar el poder.

(7) La fuente de información se registra en el SISC, Sistema de Información para la Seguridad y la Convivencia.
(8) En Colombia, la vereda es una división territorial que se ubica en la periferia de los cascos urbanos, es un área rural que depende administrativamente de las alcaldías.

(9) Partido de las Doñas (2019): partidodelasdoñas.org, fecha de consulta: 30/08/2019, https://xn--partidodelasdoas-kub.org/

(10) Morada (2019): Morada, fecha de consulta: 30/08/2019, https://morada.co/habitar/morada/colectivo/

(11) Puede consultarse en: https://www.kienyke. com/historias/jeihhco-c15-lider-social-comuna-13

(12) BENJUMEA ZAPATA, G. (2019): ITAKA. Cultura, Concepto y Conocimiento, fecha del consulta: 05/09/2019, https: / /itakacultura.com/es $/$ ?fc $=$ module $\&$ module $=$ prestablog\&controller $=$ blog\&id $=12$

(13) Secretaría de Cultura, Recreación y Deporte, fecha de consulta: 05/09/2019, https://www.culturarecreacionydeporte.gov.co/es/participacion-distrital/sistema-distrital-de-arte-cultura-y-patrimonio. 